\title{
Profiles of Organochlorine Pesticides in Earthworms from Urban Leisure Areas of Beijing, China
}

\author{
Xing-Hong Li $\cdot$ Xi-Zhi Wang $\cdot$ Wei Wang $\cdot$ \\ Xiang-Ning Jiang $\cdot$ Xiao-Bai Xu
}

Received: 21 December 2009/Accepted: 5 March 2010/Published online: 18 March 2010

(C) Springer Science+Business Media, LLC 2010

\begin{abstract}
In this study, organochlorine pesticides (HCHs and DDTs) in earthworm and soil contacted closely with it were determined for the purpose of the risk assessment of chemicals in the urban leisure environment. The level of total hexachlorocyclohexanes and ( $\mathrm{HCHs})$ and dichlorodiphenyltrichloroethanes (DDTs) in earthworms was $0.6500-44.78 \mathrm{ng} \mathrm{g}^{-1}$ and $18.97-1.112 \times 104 \mathrm{ng} \mathrm{g}^{-1}$, respectively. Absolutely high levels of DDT and its metabolites in earthworm and correlative soils samples, and the bioaccumulation factor (BAF) of DDTs probably presents certain risk to the higher trophic organisms through its food chain, especially birds.
\end{abstract}

Keywords Survey $\cdot$ DDTs $\cdot$ HCHs $\cdot$ Earthworm

Organochlorine pesticides (OCPs), such as dichlorodiphenyltrichloroethanes (DDTs) and hexachlorocyclohexanes (HCHs), have the properties of long half life time, are semi-volatile, toxic and bioaccumulative in the environment, resulting in the high risk of carcinogenic to organisms. Because of the low mobility of OCPs, which owe to its low water solubility and its strong interaction with soil components, mainly clay and organic matter, they

X.-H. Li $(\bowtie) \cdot$ X.-Z. Wang · W. Wang · X.-B. Xu

State Key Laboratory of Environmental Chemistry and Ecotoxicology, Research Center of Eco-Environment

Sciences, The Chinese Academy of Sciences,

Post Office Box 2871, 18 Shuangqing Road, Haidian District,

100085 Beijing, People's Republic of China

e-mail: 1xhzpb@rcees.ac.cn

X.-Z. Wang · W. Wang $\cdot$ X.-N. Jiang

Beijing Forestry University, 100083 Beijing,

People's Republic of China are ubiquitous anthropogenic environmental contaminants (Willett et al. 1998; Nakata et al. 1998). In contrast to agricultural soils, urban park soils which had been detected out high level OCPs, which might have a direct influence on public health since pollutants in the soils can easily be transferred into humans via ingestion, inhalation, or dermal routes, etc. ( $\mathrm{Li}$ et al. 2008). Due to the important role of urban open spaces such as parks performing in the citizens, it's necessary further to explore the probable environmental effect of OCPs from soils. Earthworms, were considered the linkage of entrance of contaminants into biology from soil and into higher food chain ulteriorly (Haque and Ebing 1983). They can also accumulate organic pollutants by dermal uptake, which makes them very suitable as models for the testing of toxic effects of OCPs on soil organisms (Beyer 1996). Therefore, the study of earthworms can supply some useful information on the risk of OCPs in urban park soils to the higher trophic organisms. The approach of the study was to provide some information on the relationship of OCPs between the soils and earthworms, to estimate the environmental risk of OCPs from the soils to the higher trophic organisms in the urban leisure facilities.

\section{Materials and Methods}

Based on the areas of the parks, surface soil samples and earthworms were collected in the studied areas of seven major districts (Xicheng, Dongcheng, Xuanwu, Chongwen, Haidian, Chaoyang and Fengtai districts) in October 2007 (Fig. 1). Each of the composite soil samples was made of 14-30 sub-samples. The samples were freeze-dried, thoroughly mixed, sieved to $30 \mathrm{mesh}$, transferred to precleaned amber glass, and maintained at $4^{\circ} \mathrm{C}$ until further 


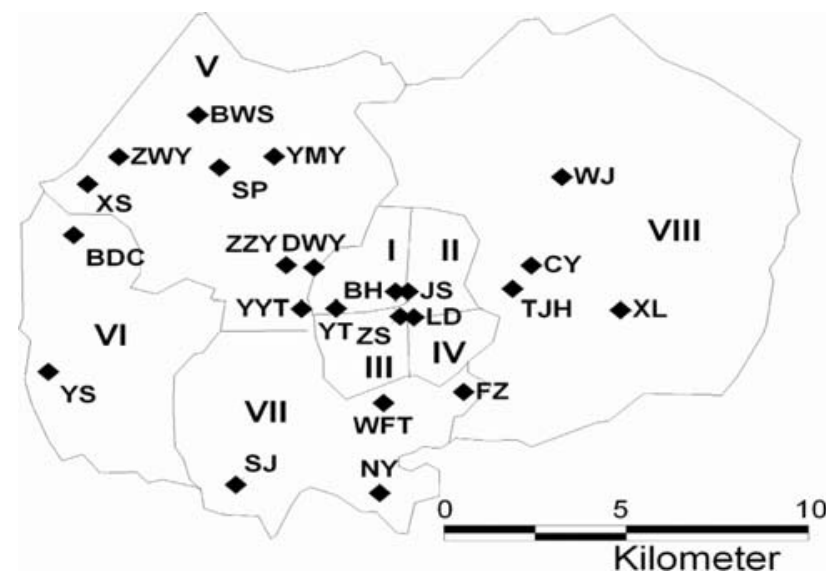

Fig. 1 Sampling sites in the parks of Beijing. I, Xicheng District; II, Dongcheng District; III, Xuanwu District; IV, Chongwen District; V, Haidian District; VI, Fengtai District; VII, Chaoyang District

processing. The earthworms were represented by the family Lumbricidae. The earthworm were colletced and kept alive until soils in their guts were cleaned out completely by placing worms on moist paper towels for $72 \mathrm{~h}$ in $1,000 \mathrm{~mL}$ glass preserving jars with no food. After washing with deionized water, earthworms were freeze-dried and stored at $-20^{\circ} \mathrm{C}$.

Primary mixed standard of eight organochlorine pesticides including $\alpha-, \beta-, \gamma-, \delta$-HCH, $\mathrm{p}, \mathrm{p}^{\prime}$-DDT, $\mathrm{p}, \mathrm{p}^{\prime}$-DDE, $o, p^{\prime}$-DDT and p, $\mathrm{p}^{\prime}$-DDD was obtained from the National Research Center for Certified Reference Materials of China at concentrations of $100.0 \mathrm{mg} \mathrm{L}^{-1} 2,4,5,6$-Tetrachloromxylene (TCMX) was purchased from Supelco (Bellefonte, PA, USA) and was used as a surrogate. The standards were further diluted with isooctane to prepare working standards. All solvents were of analytical purity (Beijing Chemical Factory, China) and were redistilled in an all-glass system before use. Silica(100-200 mesh) was purchased from Qingdao sea Chemical Factory and was activated in a drying oven at $550^{\circ} \mathrm{C}$ for $6 \mathrm{~h}$. Anhydrous sodium sulfate (Beijing Chemical Factory, China) was first washed with hexane, then heated at $600^{\circ} \mathrm{C}$ for $12 \mathrm{~h}$ before use.

In the laboratory, $5 \mathrm{~g}$ of soil and $4 \mathrm{~g}$ of earthworm samples were Soxhlet-extracted for $48 \mathrm{~h}$ with acetone:hexane $(1: 1, \mathrm{v}: \mathrm{v})$. The surrogate standards of 2,4,5,6tetrachloro-m-xylene (TCMX) was added to each of the samples prior to extraction. The extracts were concentrated, and solvent-exchanged to hexane and purified on an $20 \mathrm{~mm}$ i.d. silica column packed, from the bottom to top, with neutral silica ( $8 \mathrm{~g}, 3 \%$ deactivated), $30 \%$ (on a weight basis) sulfuric acid silica $(10 \mathrm{~g})$ and anhydrous sodium sulfate. The column was firstly pre-washed with $80 \mathrm{~mL}$ of dichloromethane/hexane (1:3) for the elimination of impurity coming from the silica gel. Then, the extracts were transferred to the top of column and the substances we interested were eluted by $100 \mathrm{~mL}$ dichloromethane/ hexane (1:4). The fraction was evaporated by rotary evaporator and adjusted to the volume appropriate for further analysis.

Quantification of organochlorine pesticides was carried out with an Agilent 6890 gas chromatography equipped with a micro-cell $63 \mathrm{Ni}$ electron capture detector ( $\mu$-ECD). The separation was performed on a fused silica capillary column (DB-5, $30 \mathrm{~m} \times 0.318 \mathrm{~mm}$ I.D., and $0.25 \mu \mathrm{m}$ film thickness). The carrier gas was nitrogen with a flow of $0.7 \mathrm{~mL} \mathrm{~min}^{-1}$. The injector and detector temperatures was 230 and $300^{\circ} \mathrm{C}$, respectively. The oven temperature was programmed as follows: initial temperature $100^{\circ} \mathrm{C}$ held for $2 \mathrm{~min}$, increased to $160^{\circ} \mathrm{C}$ at a rate of $10^{\circ} \mathrm{C} \mathrm{min}{ }^{-1}$, then increased to $280^{\circ} \mathrm{C}$ at a rate of $4^{\circ} \mathrm{C} \min ^{-1}$ and maintained for $10 \mathrm{~min}$. Sample $(1.0 \mu \mathrm{L})$ was injected in splitless mode. To confirm the results, selected typical samples were checked with a Hewlett-Parkard 6890 GC-5973 MSD system. The GC-MS parameters were the same as described above except that the carrier gas was helium. The mass spectrometer was operated in electron impact ionization mode with electron energy of $70 \mathrm{eV}$. Target compounds were monitored with selected ion monitoring (SIM) mode.

For accuracy and precision of soil analysis, it was able to refer the method from the report by Li et al. (2008). As far as the earthworms, the procedure is similar to that of soils and only the matrix blank was replaced by the edible corn oils. The average recoveries of OCPs were in the range of $65.5-97.3 \%$, and RSD was $7.7-13.8 \%(\mathrm{n}=5)$. The limits of detection (LODs) were taken as three times the response of the signal-to-noise $(\mathrm{S} / \mathrm{N})$, and LODs ranged from 0.046 to $0.119 \mu \mathrm{g} / \mathrm{kg}$. The recoveries of the TCMX surrogate were $69.3 \%-85.9 \%$ in earthworms. Since the recoveries of surrogate were satisfactory and analytical data were uncorrected in all of the samples.

\section{Results and Discussion}

The total $\mathrm{HCH}$ content in earthworms ranged from 0.6500 to $44.75 \mathrm{ng} \mathrm{g}^{-1}$ with $9.720 \mathrm{ng} \mathrm{g}^{-1}$ as the standard deviation (Table 1). The highest concentration was found in $\mathrm{TJH}$ (Tuanjiehu Park) and the lowest value was found in BWS (Baiwangshan Park). Regarding the composition of $\mathrm{HCH}$ isomers measured in this study, the average percentage of $\alpha-\mathrm{HCH}, \beta-\mathrm{HCH}$ and $\gamma-\mathrm{HCH}$ were $5.1 \%, 88.7 \%$ and $7.2 \%$, respectively. The soils associated with earthworms were also collected. All of the samples in soils contained residues of HCHs. The total $\mathrm{HCH}$ content ranged from 0.1300 to $24.02 \mathrm{ng} \mathrm{g}^{-1}$ with $6.680 \mathrm{ng} \mathrm{g}^{-1}$ as the standard deviation. As far as the compositions of $\mathrm{HCH}$ isomers measured, the average percentages of $\alpha-\mathrm{HCH}, \beta-\mathrm{HCH}$ and $\gamma-\mathrm{HCH}$ 
Table 1 Descriptive statistics of HCHs and DDTs in the earthworms of Beijing's parks (ng. $\mathrm{g}^{-1}$ )

\begin{tabular}{lllllll}
\hline & Min. & Max. & Mean & Median & $\begin{array}{l}\text { Geometric } \\
\text { mean }\end{array}$ & \\
\hline$\alpha-\mathrm{HCH}$ & 0.02000 & 0.3200 & 0.1000 & 0.1000 & 0.08000 & 0.07000 \\
$\beta$-HCH & 0.3700 & 44.33 & 5.050 & 1.870 & 2.230 & 9.650 \\
$\gamma-\mathrm{HCH}$ & $\mathrm{ND}$ & 0.3600 & 0.1300 & 0.1100 & 0.1000 & 0.09000 \\
$\Sigma$ HCHs & 0.6500 & 44.78 & 5.370 & 2.180 & 2.650 & 9.720 \\
$\mathrm{p}, \mathrm{p}^{\prime}-\mathrm{DDE}$ & 10.97 & 8,366 & 1,142 & 153.7 & 210.8 & 2,264 \\
$\mathrm{p}, \mathrm{p}^{\prime}-\mathrm{DDD}$ & 1.480 & 754.5 & 103.1 & 11.69 & 16.78 & 212.6 \\
o,p'-DDT & $\mathrm{ND}$ & 1,255 & 171.5 & 22.67 & 13.03 & 369.6 \\
$\mathrm{p}, \mathrm{p}^{\prime}-\mathrm{DDT}$ & $\mathrm{ND}$ & 3,193 & 224.8 & 22.81 & 17.94 & 684.8 \\
$\Sigma$ DDTs & 18.97 & $1.112 \mathrm{e} 4$ & 1,641 & 281.1 & 319.7 & 3,108 \\
\hline
\end{tabular}

$N D$ Not detected

were $13.5 \%, 67.2 \%$ and $20.3 \%$ respectively. The dominant percentage of metabolite $\beta$ - $\mathrm{HCH}$ indicated that there was no recent input of technical HCHs/lindane in most of the soils. Compared with the composition percentage in the earthworms, it seemed, in case of $\mathrm{HCH}$ in earthworms coming from the soil, that earthworms had less bioaccumulation or greater degradation capability to both $\alpha-\mathrm{HCH}$ and $\gamma-\mathrm{HCH}$ than $\beta$-HCH. Bioaccumulation factor (BAF) of the total $\mathrm{HCHs}$, the ratio median of contaminant concentration in earthworm to that in the soil (dry-weight), is 1.13 (Table 2), meaning the negligible/little bioaccumulation of earthworms to HCHs in the study. Simultaneously, the correlation analysis of HCHs showed it was insignificant between earthworms and soils $\left(R^{2}=0.067\right)$, which showed the little bio-availability of HCHs in the soils and its less treat to the food chain in the studied areas.

In earthworms, the total DDT concentrations ranged from 18.97 to $1.112 \times 10^{4} \mathrm{ng} \mathrm{g}^{-1}$, respectively with the standard deviation of $3,108 \mathrm{ng} \mathrm{g}^{-1}$ (Table 1). The highest value existed in LDG (Worker People's Cultural Palace) and the lowest value was in XL (Xinglong Park). The p, $\mathrm{p}^{\prime}$ DDE was the most dominant component in the total DDTs, and its percentage varied from $27.21 \%$ to $96.28 \%$ with an average of $69.57 \%$. The study of the soils associated with earthworms showed that total DDTs content ranged from
2.390 to $1,612 \mathrm{ng} \mathrm{g}^{-1}$ with $378.2 \mathrm{ng} \mathrm{g}^{-1}$ as the standard deviation. The average composition of DDT isomers in soil are p, $\mathrm{p}^{\prime}$-DDE: $47 \%$, p, $\mathrm{p}^{\prime}$-DDD: $2 \%, \mathrm{o}, \mathrm{p}^{\prime}$-DDT: $25 \%$ and $\mathrm{p}, \mathrm{p}^{\prime}$-DDT: $25 \%$. The dominance of $\mathrm{p}, \mathrm{p}^{\prime}$-DDE, inferred the metabolites formed a significant proportion of total DDT compounds in soil. However, it was noticeable that the parent compounds of both o, $\mathrm{p}^{\prime}$-DDT and $\mathrm{p}, \mathrm{p}^{\prime}$-DDT has the percentage close to $50 \%$, which probably suggested the time elapsed not too longer for the application of DDTs in soil. The ratios of $\mathrm{o}, \mathrm{p}^{\prime}-\mathrm{DDT} / \mathrm{p}, \mathrm{p}^{\prime}$-DDT was in the range of $0.1400-19.44$, and was $>0.3$ in approximate $87 \%$ samples, suggesting the important contribution of dicofol. This was also supported by the higher percentage of o, $\mathrm{p}^{\prime}$-DDT $(6.340-67.40 \%)$ in the total DDTs than that in technical DDTs product.

The level of total DDTs in earthworms were positively correlated with that in the soil, with Pearson coefficient of $0.7140(p<0.01)$, which probably indicated the transfer occurrence of DDTs from soil to the earthworms. Also, BAF was in the range of 0.1300-34.39 (median: 7.47) (Table 2) suggested that accumulation of DDTs in earthworms was occurring in most of the samples, furthermore meaning certain bio availability of DDTs in the soils and probable exposure to the food chain in the studied areas. In an early orchard study, Beyer and Gish (1980) suggested an average "storage ratio" of 5 for $\Sigma$ DDT and 16 to 6 for DDE, depending on the time following treatment. In this study, BAFs median values of SDDT (7.470) and DDE (10.20) were relatively higher values reported by Beyer and Gish (1980), probably showing the longer time after the application of DDTs.

There are substantial evidences that DDT accumulated from contaminated earthworms had killed large numbers of robins and other thrushes in the 1950s to 1970s (Barker 1958; Wallace 1962; Wurster et al. 1965; Bailey et al. 1974; Beaver 1980). Lethal brain residues in several species of bird were measured at $300-400 \mathrm{mg} \mathrm{kg}^{-1}$ (Stickel et al. 1984). Blackbirds and song thrushes found dead in a British apple orchard contained $81-128 \mathrm{mg} \mathrm{kg}^{-1}$ DDE in breast muscle, and the authors suggested that, based on the residues detected in other live birds, most thrushes in the orchard were carrying near lethal amounts of DDT (Bailey

Table 2 Total bioaccumulation of HCH and DDT in the earthworms

\begin{tabular}{|c|c|c|c|c|c|c|c|}
\hline \multirow[t]{3}{*}{ OCPs } & \multicolumn{4}{|c|}{ Concentration $\left(\mathrm{ng} \mathrm{g}^{-1}\right)$} & \multicolumn{3}{|l|}{ BAF } \\
\hline & \multicolumn{2}{|l|}{ Min. } & \multicolumn{2}{|l|}{ Max. } & \multirow[t]{2}{*}{ Min. } & \multirow[t]{2}{*}{ Max. } & \multirow[t]{2}{*}{ Mediar } \\
\hline & Soil & Earthworm & Soil & Earthworm & & & \\
\hline$\sum \mathrm{HCHs}$ & 0.1300 & 0.6500 & 24.02 & 44.78 & 0.07000 & 17.06 & 1.13 \\
\hline$\sum$ DDTs & 2.390 & 18.97 & 1,612 & $1.112 \mathrm{e} 4$ & 0.1300 & 34.39 & 7.470 \\
\hline
\end{tabular}


et al. 1974). However, in this study, the concentrations in the earthworms were much lower than the threshold value that Beyer and Gish (1980) suggested: a concentration in earthworms of $32 \mathrm{mg} \mathrm{kg}^{-1} \Sigma \mathrm{DDT}$ could be a hazard to reproduction in some bird species, implying the lower risk to the earthworms in most of leisure areas in Beijing in this present condition. Although DDTs are little risk to the worms, it was probably virulent for the higher trophic organisms in urban environment because of the bioaccumulation of DDTs through the food chain such soil-earthworm-bird.

Acknowledgments We acknowledge financial support of this work by the National Natural Science Foundation of China and the National Basic Research Program of China (20607026, 20877092) and the National High Technology Research and Development Program (“863” Program) of China (122007AA061601).

\section{References}

Bailey S, Bunyan PJ, Jennings DM, Norris JD, Stanley PI, Williams JH (1974) Hazards to wildlife from the use of DDT in orchards: II a further study. Agro-Ecosys 1:323-338

Barker RJ (1958) Notes on some ecological effects of DDT sprayed on elms. J Wildl Manage 22:269-274
Beaver DL (1980) Recovery of an American robin population after earlier DDT use. J Field Ornithol 51:220-228

Beyer WN (1996) Accumulation of chlorinated benzenes in earthworms. Bull Environ Contam Toxicol 57:729-736

Beyer WN, Gish CD (1980) Persistence in earthworms and potential hazards to birds of soil applied DDT, dieldrin and heptachlor. J Appl Ecol 17:295-307

Haque A, Ebing W (1983) Toxicity determination of pesticides to earthworms in the soil substrate. J Plant Dis Protect 90:395-408

Li XH, Wang W, Wang J, Cao XL, Wang XF, Liu JC, Liu XF, Xu XB, Jiang XN (2008) Contamination of soils with organochlorine pesticides in urban parks in Beijing, China. Chemosphere 70:1660-1668

Nakata H, Kannan K, Jing LL, Thomas N, Tanabe S, Giesy JP (1998) Accumulation pattern of organochlorine pesticides and polychlorinated biphenyls in southern sea otters (Enhydralutris nereis) found stranded along coastal California, USA. Environ Pollut 103:45-83

Stickel WH, Stickel LF, Dryland RA, Hughes DL (1984) DDE in birds: lethal residues and loss rates. Arch Environ Contam Toxicol 13:1-6

Wallace GJ (1962) The seventh spring die-off of robins at East Lansing, Michigan. Jack-Pine Warbl 40:26-32

Willett KL, Ulrich EM, Hite A (1998) Differential toxicity and environmental fates of hexachlorocyclohexane isomers. Environ Sci Technol 32:2197-2207

Wurster DH, Wurster CF, Strickland WN (1965) Bird mortality following DDT spray for Dutch elm disease. Ecology 46:488499 